\title{
Colchicine cardiotoxicity following ingestion of Gloriosa superba tubers
}

\author{
Shanthi Mendis
}

Department of Medicine, Faculty of Medicine, Peradeniya, Sri Lanka.

\begin{abstract}
Summary: The clinical features of colchicine toxicity in a patient following ingestion of Gloriosa superba tubers are described. Gastroenteritis, acute renal failure, cardiotoxicity and haematological abnormalities were the main toxic manifestations. There was no hypotension and no neurological manifestations. Electrocardiographic changes were noteworthy and have not been reported previously.
\end{abstract}

\section{Introduction}

Gloriosa superba is a plant that grows wild in all parts of Sri Lanka. The tubers of this plant have been found to contain several alkaloids among which colchicine and gloriosine are the most important ones. ${ }^{1}$ Acute intoxication associated with the ingestion of Gloriosa superba is indistinguishable from the clinical features of colchicine poisoning.

\section{Case report}

A 29 year old man who attempted suicide by ingesting tubers of Gloriosa superba was admitted 4 hours later to Teaching Hospital Peradeniya, complaining of burning in the mouth and throat, intense thirst, nausea, vomiting and abdominal colics. On examination he was restless, afebrile and dehydrated. Pulse rate was 90 beats $/ \mathrm{min}$. Blood pressure was $100 /$ $70 \mathrm{mmHg}$ and respiratory rate was 20 per minute. Gastric lavage was performed and he was given intravenous fluids. Except for an elevated haematocrit $(P C V=0.541 / 1)$ his biochemical and haematological investigations were normal on admission.

He was oliguric for 24 hours. By the second day the blood urea increased to $10.3 \mathrm{mmol} / \mathrm{l}$ and urinalysis showed proteinuria and mild haematuria. He developed a watery diarrhoea, complained of severe body ache and generalized chest pain. An electrocard-

Correspondence: S. Mendis, M.B., B.S., D.M., M.R.C.P. (UK), Department of Pathological Biochemistry, Queen Elizabeth's Building, Phase 1, 4th floor, Glasgow Royal Infirmary, Glasgow G4 OSF, UK.

Accepted: 28 April 1989 iogram done at this stage was normal. Serum aspartate transaminase was $10 \mathrm{IU} / 1$ (normal $0-12$ ). Serum alanine transaminase was $20 \mathrm{IU} / 1$ (normal $0-11$ ) serum bilirubin was $17 \mathrm{mmol} / 1$, plasma potassium was $4.2 \mathrm{mmol} / \mathrm{l}$ and plasma sodium was $138 \mathrm{mmol} / \mathrm{l}$. Op the third day the patient complained of severe pain alf over the chest associated with difficulty in breathing? His respiratory rate was $38 / \mathrm{min}$, pulse was 100 beats/ min regular, and blood pressure $110 / 70 \mathrm{mmHg}$. He had a triple rhythm and bilateral basal crepitations.

The electrocardiogram (Figure 1) showed ST elevation. Aspartate transaminase rose to over $60 \mathrm{IU} / 1$ (normal 0-12), creatine kinase was 40/IU/l (normal $0-12$ ) and serum cholesterol was $5.0 \mathrm{mmol} / \mathrm{l}$. He was treated with analgesics and frusemide. He continued to complain of chest pain on the fourth day. The electrocardiogram showed further $T$ elevation (Figure 2). By the fifth day he developed bleeding gums and subconjunctival haemorrhages and haematuria. At this stage haematological investigations showed haemoglobin $9.5 \mathrm{~g} / \mathrm{dl}$, white cell count $2.8 \times 9^{9} / 1$, platelet count $20 \times 10^{9} / 1$, bleeding time 3 minutes, clotting time 11 minutes, prothrombin time 18 seconds (control 15 seconds).

He was transfused three pints of fresh blood in the next 48 hours. Serum aspartate transaminase and creatine kinase returned to normal by the ninth day. The electrocardiogram showed only inverted $T$ waves in V5.

His condition gradually improved and 3 weeks after admission he was transferred to the Department of Psychiatry for further management. Biochemical and haematological investigations and the electrocardiogram (resting and in response to exercise) were normal. 


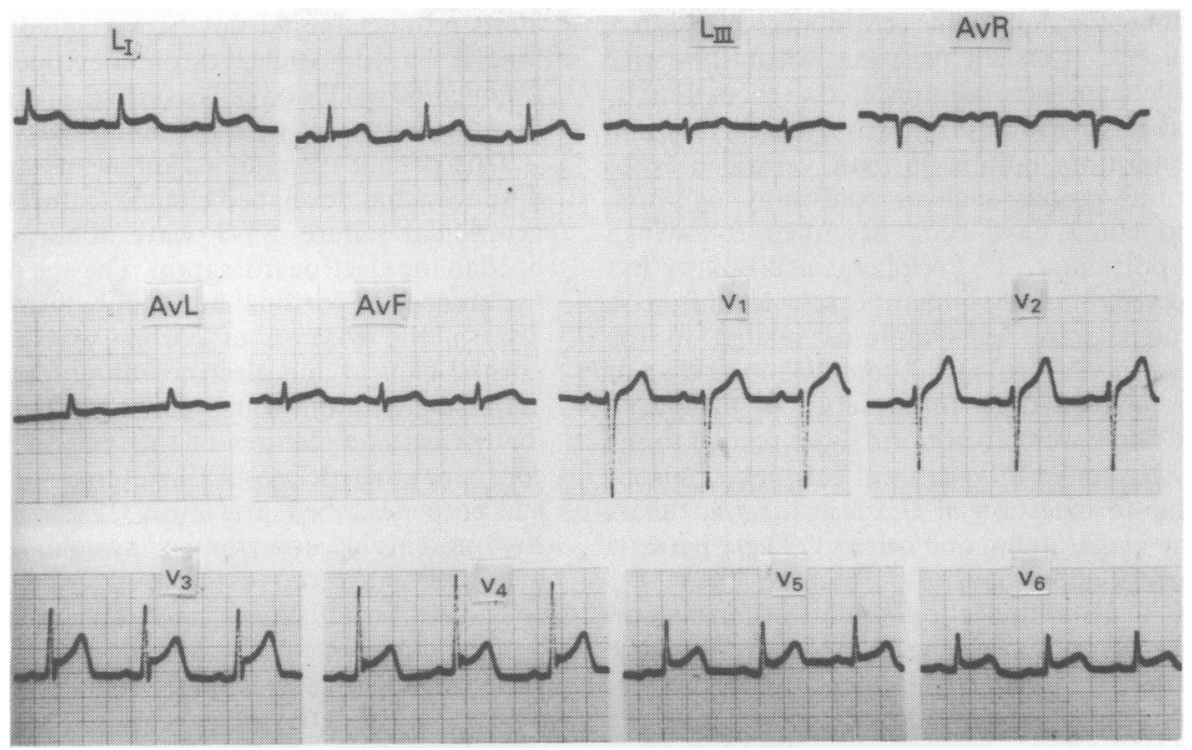

Figure 1 Electrocardiograph recording 3rd day after admission.

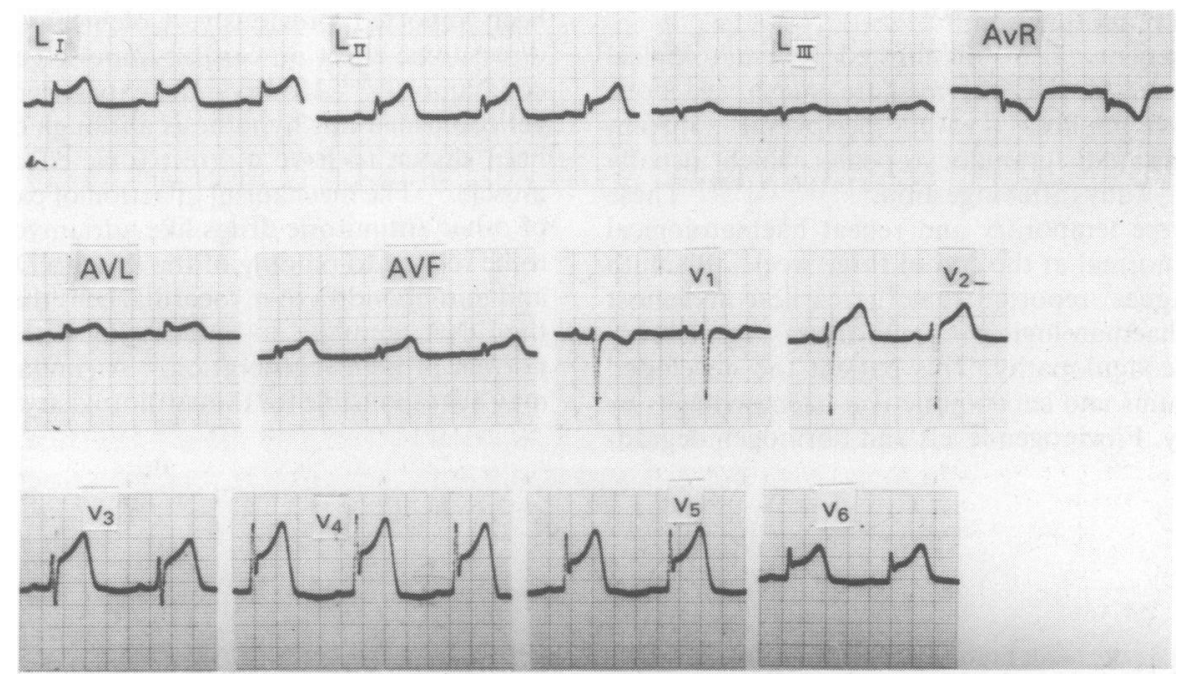

Figure 2 Electrocardiograph recording 4th day after admission.

\section{Discussion}

There does not appear to be a clear separation of non-toxic, toxic and lethal dosages of colchicine. ${ }^{2-5}$ This patient had ingested about 100 grams of tuber. Dunuwille and others ${ }^{1}$ have estimated that $10 \mathrm{~g}$ of fresh tuber contains approximately $6.0 \mathrm{mg}$ of colchicine. Therefore the amount of colchicine ingested by this patient is in the region of $60 \mathrm{mg}$. Fatalities have been reported with doses as small as $7 \mathrm{mg}{ }^{6}$ Bismuth and colleagues ${ }^{7}$ reported that patients who ingested more than $0.8 \mathrm{mg} / \mathrm{kg}$ of colchicine died while those who ingested less than $0.5 \mathrm{mg} / \mathrm{kg}$ survived.

The commonest clinical presentation of poisoning with colchicine is one of severe gastroenteritis. Severe vomiting and diarrhoea causing fluid loss severe enough to produce hypotension has been reported. ${ }^{8,9}$ This patient, too, had nausea, vomiting and watery diarrhoea at the time of admission.

Colchicine has been shown by Ferguson ${ }^{10}$ to have its 
most prominent action on the central nervous system. Rats developed transient paralysis when sub-lethal doses of colchicine were administered to them. Fatally intoxicated rats became progressively paralysed and died of respiratory failure. In man, central nervous system manifestations such as confusion, delirium, stupor and coma have been described following3 colchicine poisoning. ${ }^{11-13}$ Peripheral neuropathy has been observed in four human cases. In this case however there were no symptoms related to the nervous system. Neurological complications do not appear to be related to the severity of colchicine poisoning. There were no abnormalities related to the nervous system in six fatal cases of colchicine poisoning also due to ingestion of Gloriosa superba tubers reported by Nagaratnam and others. ${ }^{16}$ These patients died between 1 and 8 days of poisoning.

Oliguric renal failure is a common occurrence in severe colchicine poisoning. ${ }^{3,6,9,11,12,14,17,18,19}$ Urine abnormalities such as proteinuria, myoglobinuria, haematuria and pyuria are described in the literature. ${ }^{3,9,17,18,20}$ This patient too was oliguric the first day and developed proteinuria and haematuria. The combined effects of hypotension, myoglobinuria and direct toxicity probably contribute to the abnormalities in renal function. ${ }^{20,21}$

This patient also manifested haematological features seen in the intermediate stage, i.e. bone marrow hypoplasia with peripheral thrombocytopenia and granulocytopenia which usually manifest $4-7$ days after ingestion. ${ }^{2,3,9,11,12,14,18,20,22}$ These changes were temporary and repeat haematological tests were normal at the end of three weeks. Bismuth and colleagues ${ }^{7}$ reported that the earliest and most common haematological complication was a consumption coagulopathy. This patient too developed bleeding gums and subconjunctival haemorrhages by the 5th day. Fibrinogen levels and fibrinogen degrad-

\section{References}

1. Dunuwille, R., Balasubramanium, K. \& Bibile, S.W. Analysis of alkaloids in Gloriosa superba. Ceylon J Med Sci 1968, 17: 1.

2. Liu, Y.K., Hymowitz, R. \& Carroll, M.G. Marrow aplasia induced by colchicine. A case report. Arthritis Rheum 1978, 21: 731-735.

3. Ellwood, M.G. \& Robb, G.H. Self poisoning with colchicine. Postgrad Med J 1971, 47: 129-131.

4. Jarvie, D., Park, J. \& Stewart, M.J. Estimation of colchicine in a poisoned patient by using high performance chromatography. Clin Toxicol 1979, 14: 375-381.

5. Wallace, S.L. Colchicine. Semin Arthritis Rheum 1974, 3: 369-381.

6. MacLeod, J.G. \& Philips, L. Hypersensitivity to colchicine. Ann Rheum Dis 1947, 6: 224-229. ation products could not be measured but the pro- $\frac{a}{3}$ longed clotting time, thrombocytopenia and the $\underset{\propto}{\mathscr{Q}}$ fragmented red blood cells seen in the peripheral blood $c$. film are consistent with consumption coagulopathy. $\vec{F}$

This patient complained of severe chest pain and $\stackrel{\vec{F}}{+}$ dyspnoea and developed clinical features of acute left $\frac{}{C}$ ventricular failure. ST-T wave abnormalities devel-흠 oped in the electrocardiogram. The age of the patient, $\frac{\text { }}{\frac{}{\sigma}}$ the absence of personal and family history of cardiac $\varrho$ disease, the absence of coronary risk factors and $\%$ normal clinical and electrocardiographic findings at $\vec{\circ}$ admission and follow up, makes it extremely unlikely for the cardiac features of this patient to be due to $\vec{\omega}$ coronary atherosclerosis. Cardiotoxicity of colchicine $\frac{\Omega}{D}$ has been described previously. Tachycardia, gallope rhythm, cardiac arrhythmias, systolic murmurs and $\underline{3}$. hypotension are known to occur. ${ }^{7,21,23}$ Sauder and his of colleagues $^{24}$ performed haemodynamic studies in $\sigma$ 8 cases of colchicine poisoning and reported that $\infty$ impairment of cardiac performance which can be ov detected in the initial stages of poisoning is an index of ${ }^{N}$

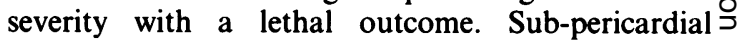
haemorrhages and changes consistent with myocard- $\overrightarrow{0}$ itis have also been seen at autopsy. ${ }^{16}$ However, electrocardiographic changes as seen in this case have not $\frac{0}{0}$ been reported previously. Colchicine may have $\stackrel{\square}{\Phi}$ direct toxic effect on cardiac impulse generation ar $\overrightarrow{0}$ conduction. ${ }^{4,20,21}$ However, no experimental study ha yet confirmed this hypothesis although colchicine h通. been shown to have a direct toxic effect on skelet muscle. ${ }^{25}$ The mechanism of action of cardiac toxicity of other antimitotic drugs like adriamycin is thought to be related to binding of the drug to DNA in nuclei and mitochondria of myocardial cells thereby altering $\bigcirc$ the DNA template and interfering with processes of $\overrightarrow{\overrightarrow{0}}$ normal protein regeneration. ${ }^{26} \mathrm{~A}$ similar mechanism may be responsible for the cardiotoxicity of colchicine.

7. Bismuth, C., Gaultier, M. \& Conso, F. Aplasie medul-o laire apres intoxicationaigue a la colchicine. Nouv Presse Med 1977, 6: 1625-1629.

8. Gooneratne, B.W.M. Massive generalized alopecia after poisoning by Gloriosa superba. Br Med J 1966, 1: N $1023-1024$.

9. Naidus, R.M., Rodvin, R. \& Mielke, H. Colchicine $\stackrel{ }{\circ}$ toxicity. A multisystemic disease. Arch Intern Med 1977, 137: $394-396$.

10. Ferguson, J.C. Colchicine I. General pharmacology. Pharmacol Exp Ther 1952, 106: $261-270$.

11. Carr, A.A. Colchicine toxicity. Arch Intern Med 1965, 115: $29-33$. 
12. Boruchow, I.B. Bone marrow depression associated with acute colchicine toxicity in the presence of hepatic dysfunction. Cancer 1966, 19: 541-543.

13. Bruns, B.G. Colchicine toxicity. Aust Ann Med 1968, 17: $341-344$.

14. Dobbs, A.G., Lawrence, P.J. \& Biggs, J.C. Colchicine overdose. Med J Aust 1978, 2: 91-92.

15. Agunawela, R.M. \& Fernando, H.A. Acute ascending polyneuropathy and dermatitis following poisoning by tubers of Gloriosa superba. Ceylon Med J 1971, 16: 233-235.

16. Nagaratnam, N., De Silva, D.P.K.M. \& De Silva, N. Colchicine poisoning following ingestion of Gloriosa superba tubers. Trop Geog Med 1973, 25: 15-17.

17. Hill, R.N., Spragg, R.G., Weldel, M.K. et al. Adult respiratory distress syndrome associated with colchicine intoxication. Ann Intern Med 1975, 83: 523-524.

18. Heaney, D. Dergharzarian, C.B., Pineo, G.F. et al. Massive colchicine overdose: a report on the toxicity $\mathrm{Am}$ J Med Sci 1976, 271: 233-238.

19. Dominguez de Villota, E., Galdos, P., Mosquera, J.M. et al. Colchicine overdose: an unusual origin of multiorgan failure. Crit Care Med 1979, 7: 278-279.
20. Stemmermann, G.N. \& Hayashi, T. Colchicine intoxication. A reappraisal of its pathology based on a study of three fatal cases. Hum Pathol 1971, 2: 321-332.

21. Stahl, N., Weinberger, A., Benjamin, D. et al. Fatal colchicine poisoning in a boy with familial Mediterranean fever. Am J Med Sci 1979, 278: 77-81.

22. Cohen, S. \& Johnson, J.R. Clinical experience with intravenous colchicine with inoperable bronchogenic carcinoma. Dis Chest 1960, 38: 30-41.

23. Ertel, N.H., Omokoku, B. \& Wallace, S.L. Colchicine concentration in leukocytes (abstract). Arthritis Rheum 1969, 12: 293.

24. Sauder, Ph., Kopferschmitt, J., Jaeger, A. \& Mantz, J.M. Haemodynamic studies in eight cases of acute colchicine poisoning. Human Toxicol 1983, 2: 169-173.

25. Markland, O.N. \& D'Agostino, A.N. Ultrastructural changes in skeletal muscle induced by colchicine. Arch Neurol 1971, 24: 72-82.

26. Malwista, S.E. Colchicine: a common mechanism for its anti-inflammatory and anti-mitotic effects. Arthritis Rheum 1968, 11: 191-197. 